\title{
Reference Values for Blood Flow Velocity in the Uterine Artery in Normal Pregnancies from 18 Weeks to 42 Weeks of Gestation Calculated by Automatic Doppler Waveform Analysis
}

Dopplersonografische Referenzkurven von der Arteria uterina in einer Normalpopulation zwischen 18 und 42 Schwangerschaftswochen berechnet anhand einer automatischen Hüllkurvenanalyse

Authors

Affiliations
F. Bahlmann ${ }^{1}$, M. Fittschen ${ }^{1}$, I. Reinhard ${ }^{2}$, S. Wellek ${ }^{3}$, E. Steiner ${ }^{4}$

Obstetrics and Gynecology, Bürgerhospital, Frankfurt

Department of Biostatistics, University of Mannheim

Biostatistics, University of Mannheim

Obstetrics and Gynecology, Klinikum Rüsselsheim

\section{Key words \\ - doppler \\ - reference values \\ - regression function \\ uterine artery \\ - pregnancy}

received $\quad 17.10 .2010$

accepted 16.6.2011

Bibliography

DOI http://dx.doi.org/10.1055/

s-0031-1281647

Published online

January 24, 2012

Ultraschall in Med 2012; 33:

258-264 @ Georg Thieme

Verlag KG Stuttgart · New York . ISSN 0172-4614

\section{Correspondence \\ Dr. Franz Bahlmann}

Obstetrics and Gynecology,

Bürgerhospital

Nibelungenallee $37-41$

60318 Frankfurt

Tel.: ++49/69/1500412

Fax: ++49/69/1500400

f.bahlmann@buergerhospital-

ffm.de

\section{Zusammenfassung}

$\nabla$

Ziel: Die vorliegende Studie wurde mit dem Ziel durchgeführt, neue Normkurven für die mütterliche Herzfrequenz, die mittleren intensitätsgewichteten Flussgeschwindigkeiten (Vmean) und die Gefäßwiderständen (PI, RI) mithilfe einer automatisierten Hüllkurvenanalyse von der A. uterina zu erstellen.

Material und Methoden: Eine prospektive Querschnittsstudie bei 921 normalen Schwangerschaften wurde zwischen 18-42 Schwangerschaftswochen durchgeführt. Die uterinen Blutflussgeschwindigkeiten wurden mittels farbkodierter gepulster Doppersonografie standardisiert abgeleitet. Die uterinen Dopplermessungen wurden 1-2 cm oberhalb der Kreuzungstelle der A. iliaca externa durchgeführt. Für die einzelnen Dopplerparameter der A. uterina erfolgte die Konstruktion von Referenzbändern basierend auf einer Wachstumsfunktion einer 4-parametrischen Klasse monotoner Funktionen, die durch kleinste Quadrateanpassung bestimmt wird.

Ergebnisse: Ein signifikanter Anstieg der intensitätsgewichteten mittleren uterinen Blutflussgeschwindigkeiten wurden zwischen der 18. und 42. Schwangerschaftswoche beobachtet (Vmean $=43 \mathrm{~cm} / \mathrm{s}$ bis $50 \mathrm{~cm} / \mathrm{s}(\mathrm{p}<0,001)$. Die Pulsatilitäts- und Resistenzeindizes (PI, RI) zeigten mit zunehmendem Gestationsalter eine signifikante Abnahme (PI: 18. SSW: 0,89; 42. SSW: 0,65 und RI: 18. SSW: 0,45; 42. SSW: 0,35). Beim Vergleich der Plazentalokalisationen fanden sich keine signifikanten Unterschieden für den Pulsatilität- und den Resistenzindex. Die maternale Herzfrequenz fiel von $88 \mathrm{Spm}$ auf 77 Spm $(\mathrm{p}<0,001)$.

Schlussfolgerung: Neue dopplersonografische Referenzkurven von den Blutflussgeschwindigkeiten der A. uterina und den Widerstandsindizes (PI, RI) konnten an einem Normalkollektiv errechnet werden. Die vorliegenden Normkurven können als

\section{Abstract \\ $\nabla$}

Purpose: The goal of the present study was to establish new Doppler reference ranges for maternal heart rate, intensity-weighted mean blood flow velocities (Vmean) and impedance indices (PI, RI) for the uterine artery by automated waveform analysis.

Materials and Methods: A cross-sectional prospective study of 921 low-risk pregnancies was performed at $18-42$ weeks of gestation. Uterine blood flow velocities were derived with pulsedwave color Doppler. Measurements were carried out 1 to $2 \mathrm{~cm}$ above the crossing of the uterine and external iliac arteries. Reference ranges for the individual measuring parameters were constructed based on a growth function from a fourparameter class of monotonic continuous functions according to the smallest square principle.

Results: A significant increase in intensityweighted mean uterine blood flow velocities was observed at 18-42 weeks of gestation $($ Vmean $=43 \mathrm{~cm} / \mathrm{s}$ to $50 \mathrm{~cm} / \mathrm{s}(\mathrm{p}<0.001)$ ). Reference curves for the pulsatility and resistance indices (PI, RI) significantly decreased with progressing gestation (PI: 18 weeks: $0.89 ; 42$ weeks: 0.65 and RI: 18 weeks: $0.45 ; 42$ weeks: 0.35 ). No significant PI and RI differences were observed when different placental locations were compared. The maternal heart rate decreased from $88 \mathrm{bpm}$ to $77 \mathrm{bpm}$.

Conclusion: Normal ranges for blood flow velocities and impedance indices in the uterine artery were established by Doppler ultrasound antenatal examinations of a large population of low-risk pregnancies. The data are proposed as reference curves to allow the early diagnosis of maternal and fetal risks. 
Referenzwerte für den frühzeitigen Nachweis einer maternalen und fetalen Gefährdung herangezogen werden.

\section{Introduction}

Doppler ultrasound measurements of the uteroplacental blood flow and its relevance for the early detection of gestational risks was first reported by Campbell et al. in 1983 [1]. Subsequent studies showed that a persistently increased pulsatility index throughout the second half of gestation and particularly the confirmation of a post-systolic notch in the uterine arteries were often accompanied by pregnancy-induced hypertension, preeclampsia, intrauterine growth restriction, placental abruption and intrauterine death [2-7].

Uterine Doppler measurements were predominantly performed using transvaginal sonography $[8,9]$ in the first half of gestation and by means of abdominal sonography in the second half of gestation $[4,5,10]$. Initially, Doppler velocimetry of the uterine artery was performed by continuous-wave measurements $[3,6$, 11-13]. Pulsed Doppler spectral analysis [1, 7, 14] and Doppler color flow imaging techniques $[4,5,10,15]$ represented significant methodological improvements. In order to differentiate normal from pathological uterine waveforms, the definition of a normal range during pregnancy is very important. However, many reference ranges are associated with methodological flaws [16-18]. The validity of several reference ranges has been limited by small case numbers, the use of a single measuring parameter, longitudinal or cross-sectional studies, a short observation period, a lack of information about case numbers studied at the various time points from week 18 to 42 of gestation, differing techniques to obtain waveforms, differing sampling sites for Doppler measurements, calculation of raw data by inconsistently applied and inadequately explained mathematical methods, as well as by an insufficiently defined patient population. Therefore, the present study intends to establish new Doppler ultrasound gestational age-dependent reference curves for the uterine artery (PI, RI, $\mathrm{V}_{\text {mean }}$ ) in a normal obstetric population obtained by color Doppler measurements from the $18^{\text {th }}$ to $42^{\text {nd }}$ week of gestation. To this end, a mathematical growth model was developed by our group on the basis of validated methodological guidelines.

\section{Patients and Methods \\ $\nabla$}

Doppler ultrasound examinations of the uterine artery were performed in a prospective cross-sectional study of 921 lowrisk pregnancies, from 18-42 completed weeks of gestation. Every patient underwent only one examination. Gestational age was calculated from the last menstrual period, confirmed by first trimester crown-rump length measurement and corrected as required [19]. At the time of examination, the fetal abdominal and head circumference had to be within the $90 \%$ confidence interval of our standard curves [20]. An amniotic fluid volume within the normal range represented an additional inclusion criterion. Furthermore, only patients with normal findings regarding impedance indices (PI, RI) in the umbilical artery were included in the study. Smokers were required to abstain from smoking for at least two hours prior to examination. The exclusion criteria included: intrauterine growth restriction, hypertensive diseases, preeclampsia, ma- ternal coagulation disease, diabetes, collagen vascular disease, pharmacotherapy and drug dependence, uterine malformations, labor activity and maternal emotional states. Further uterine Doppler flow waveforms with the presence of a unilateral or bilateral post-systolic notch were excluded. The ultrasound investigations were performed with a $2-5 \mathrm{MHz}$ broadband transducer and a $2.25 \mathrm{MHz}$ transducer (Combison 530/530 MT, Kretz-Technik, Austria and Voluson 730 expert GE Medical systems) was used to derive the blood flow velocities. The ultrasound transducer was positioned on the lower lateral side of the abdomen. Color Doppler imaging was performed to visualize the uterine artery and optimize the insonation by pulsed-wave Doppler ( Fig. 1, 2). Uterine

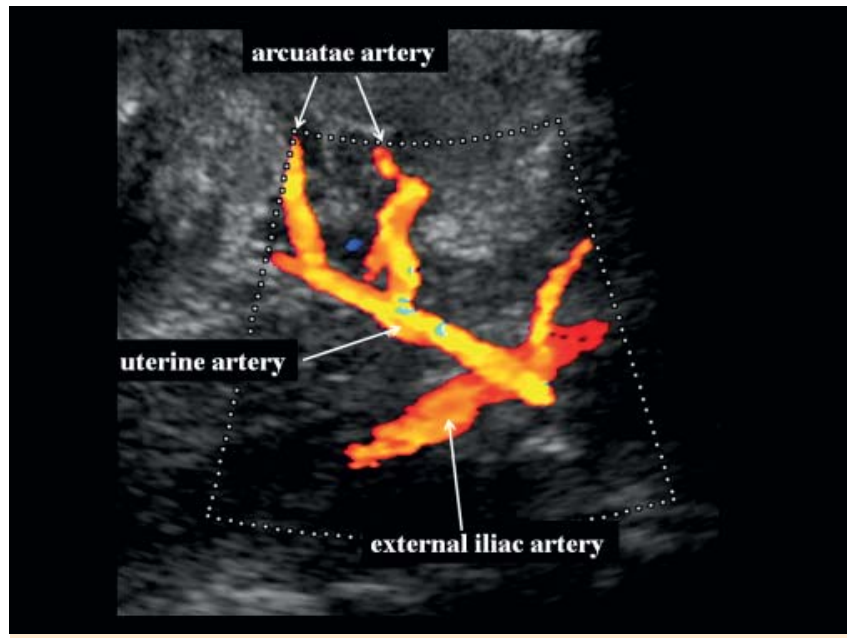

Fig. 1 Color flow imaging shows the complex uterine circulation in the lower lateral abdominal quadrant.

Abb. 1 Farbdoppersonografische Darstellung des uteroplazentaren Kreislauf im lateralen unteren Quadranten des Abdomens.

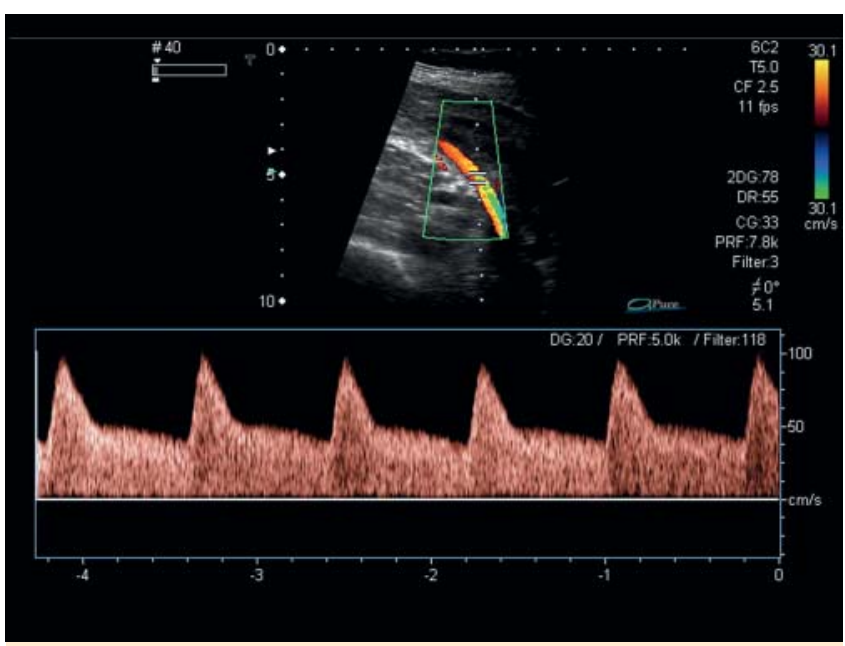

Fig. 2 Transabdominal color flow imaging and normal Doppler velocity waveforms of the uterine artery.

Abb. 2 Transabdominale farbdopplersonografische Darstellung eines normalen uterinen Dopplerflussspektrums. 
flow velocities were taken approximately $1 \mathrm{~cm}$ to $2 \mathrm{~cm}$ above the crossover of the external iliac artery on both sides ( $\bullet$ Fig. 2). Doppler measurements were performed according to the guidelines of the International Perinatal Doppler Society [21]. Only patients with an anterior, posterior or fundal location of the placenta were examined. The mean PI, RI and $\mathrm{V}_{\text {mean }}$ of the right and left uterine artery were calculated. The pulse repetition frequency ranged from 4 to $6 \mathrm{kHz}$ and the wall filter was set at $120 \mathrm{~Hz}$. The angle of insonation was below $30^{\circ}$ for all measurements. Calculations for 3 uniform heart cycles were made from the stored image using an automatic waveform analysis integrated into the ultrasound device. The pulsatility and resistance indices (PI, RI), intensity-weighted mean velocity $\left(\mathrm{V}_{\text {mean }}\right)$ and maternal heart rate (MHR) were calculated automatically from the mean values. The spatial average intensity for color and pulsed Doppler was consistently less than $100 \mathrm{~mW} / \mathrm{cm} 2$. All measurements were performed by one investigator (F.B.) with extensive Doppler sonography experience.

\section{Statistical method for creating age-dependent reference percentiles}

Reference ranges for the respective gestational weeks were determined with the aim of creating smoothened growth curves for the entire gestational period. For this purpose, the statistical method suggested by Wellek et al. (1995) was used and is briefly described below [22]:

1. The boundaries of the bands were shown as smoothened curves instead of as step or piece-wise linear functions.

2. The central line of the band was determined by fitting a nonlinear regression function derived from a sufficiently flexible class of monotonic functions parametrized as parsimoniously as possible. The following model describes a class of monotonic functions which proved to be very well-suited for this purpose: $\mathrm{g}(\mathrm{t})=\mathrm{c} \times\left(\mathrm{d}+\mathrm{I}_{\left(\mathrm{t}-\mathrm{t}^{\prime}\right) /\left(\mathrm{t}^{\prime \prime}-\mathrm{t}^{\prime}\right)}\right)(\mathrm{a}, \mathrm{b})$,

where $t^{\prime}$ and t" denote the upper limit of the time range, respectively, and $I x(a, b)$ stands for the value of the beta distribution function with parameters $(a, b)$ at $\mathrm{x}$, for any point $\times$ in the unit

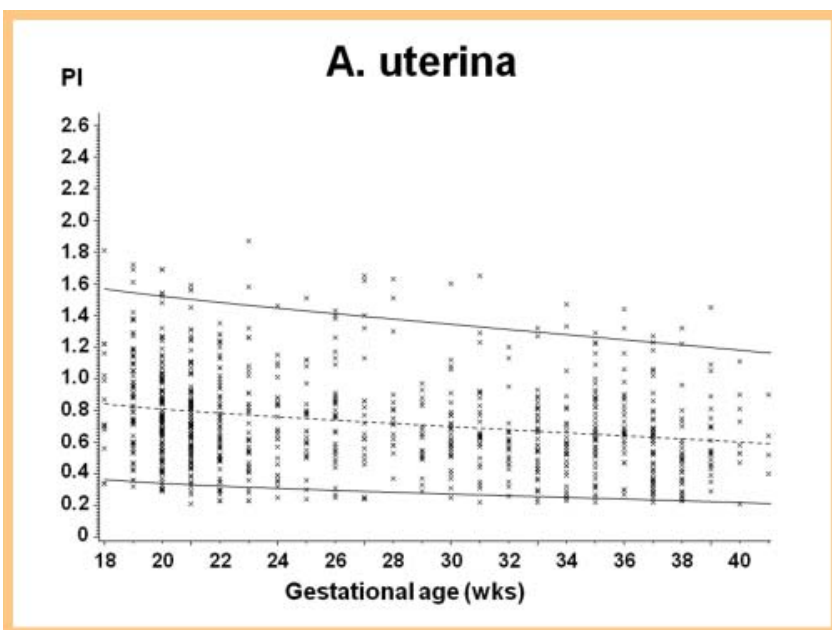

Fig. 3 Individual measurements and calculated reference ranges for the pulsatility index (PI) in the uterine artery. The standard boundaries include $90 \%$ of the normal patient population.

Abb. 3 Darstellung der Einzelmessungen für den Pulsatilitätsindex (PI) der A. uterina. Das Konfidenzintervall beinhaltet $90 \%$ des Normalkollektivs. interval (0.1). Of the four parameters involved in the model, the first two, i.e., $a$ and $b$ determine the form of the curve, while $c$ and $d$ reflect the scale and order of magnitude. In addition, the sign of $c$ coincides with that of the slope of the curve.

3. The boundary curves were determined so that the width of the band increases or decreases linearly from left to right according to the ratio of the conditional standard deviations observed in the first and the last decile with respect to gestational age. For the majority of the measurements analyzed in this paper, variability increased with the observation time points leading to increasing bandwidths.

4. Subject to condition (III), the smallest bandwidth was computed to provide a minimum coverage of $90 \%$ for the individual observations contained in the reference sample. In nonsymmetrical cases, the proportion of points outside the band is controlled separately for the lower and the upper part, in order to obtain (approximate) equality of tails. In other words, in all diagrams and tables, the lower and upper boundaries correspond as closely as possible to the 5th and 95th percentiles, respectively. This obviously entails more or less marked differences between the upper and the lower reference curves with respect to the distance from the regression line.

\section{Results}

$\nabla$

In 921 cases good Doppler flow spectra were derived from the left and right uterine artery. The ranges are shown in $\odot$ Figs. 36 and $\triangle$ Table 1 and 2 . The reference curve of the pulsatility index (PI) is characterized by a linear pattern, showing a decrease of 0.89 to 0.65 from the $18^{\text {th }}-42^{\text {nd }}$ week of gestation. A similar pattern was observed for the resistance index (RI) with a decrease of 0.45 to 0.35 . The maternal heart rate decreased from $88 \mathrm{bpm}$ in the $18^{\text {th }}$ week to $77 \mathrm{bpm}$ in the $42^{\text {nd }}$ week of gestation.

With regard to intensity-weighted mean blood flow velocities $\left(V_{\text {mean }}\right)$, an increase of 43 to $50 \mathrm{~cm} / \mathrm{s}$ was noted for the observa-

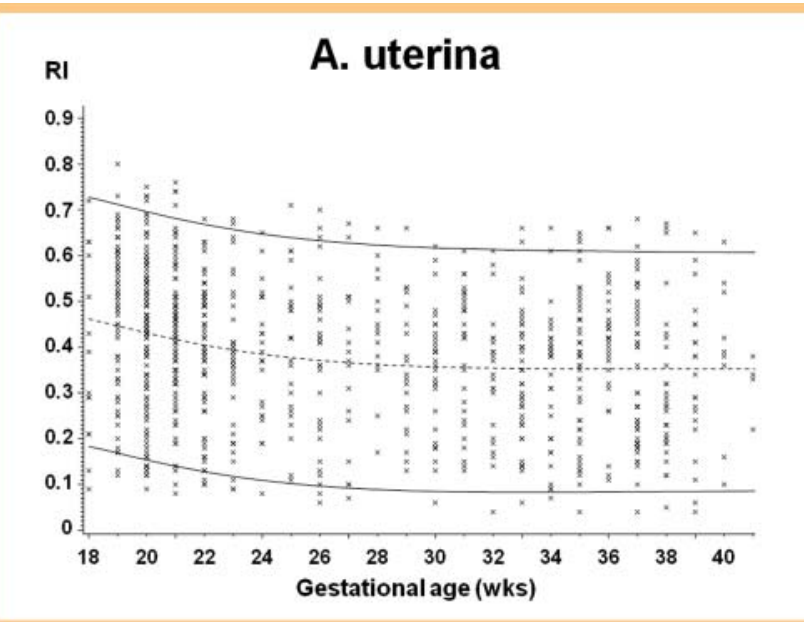

Fig.4 Individual measurements and calculated reference ranges for the resistance index (RI) in the uterine artery. The standard boundaries include $90 \%$ of the normal patient population.

Abb. 4 Darstellung der Einzelmessungen für den Resistenzindex(RI) der A. uterina. Das Konfidenzintervall beinhaltet $90 \%$ des Normalkollektivs. 
tion interval. The regression models fitted to the data of the variables under consideration are summarized in 0 Table 3.

The impedance indices for the placental positions (anterior, posterior, fundal) were compared in 10 patients and showed no significant differences. Comparisons of our reference values for the pulsatility index (PI) and resistance index (RI) were performed with the results of the literature and are presented in $\bigcirc$ Fig. 7, 8.

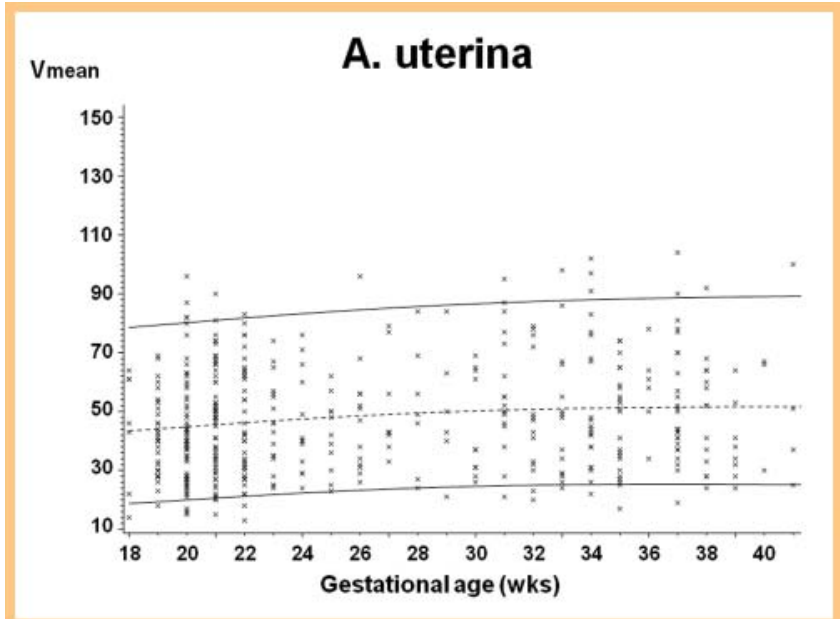

Fig. 5 Individual measurements and calculated reference ranges for the intensity-weighted mean blood flow velocity (Vmean) in the uterine artery. The standard boundaries include $90 \%$ of the normal patient population.

Abb.5 Darstellung der Einzelmessungen für die mittlere intensitätsgewichtete Flussgeschwindigkeit (Vmean) der A. uterina. Das Konfidenzintervall beinhaltet $90 \%$ des Normalkollektivs.

\section{Discussion}

$\nabla$

The present study examined parameters of uterine blood flow velocity and impedance indices as well as the maternal heart rate in a large, well-defined low-risk population of pregnancies. Evaluation of 921 women between the $18^{\text {th }}$ and $42^{\text {nd }}$ week of pregnancy demonstrated a significant increase in the blood flow velocity ( $\left.\mathrm{V}_{\text {mean }}\right)$ of the uterine artery and significant decreases of uterine resistance indices (PI, RI) as well as a decrease of the maternal heart rate.

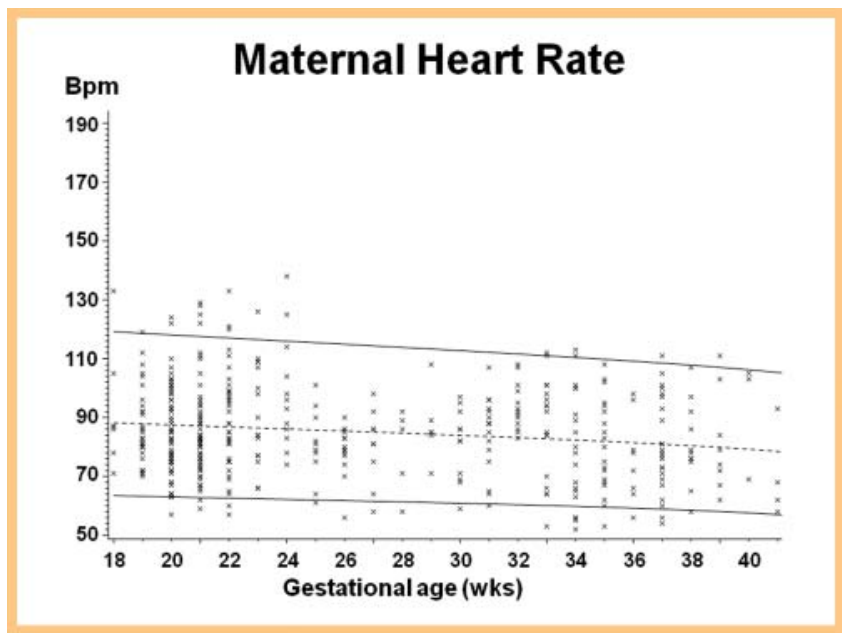

Fig. 6 Individual measurements and calculated reference ranges for the maternal heart rate. The standard boundaries include $90 \%$ of the normal patient population.

Abb.6 Darstellung der Einzelmessungen für die mütterliche Herzfrequenz. Das Konfidenzintervall beinhaltet $90 \%$ des Normalkollektivs.

Tab. 1 Pulsatility index (PI), resistance index (RI) and intensity-weighted mean velocity $\left(\mathrm{V}_{\text {mean }}\right)$ of the uterine artery.

\begin{tabular}{|c|c|c|c|c|c|c|}
\hline $\begin{array}{l}\text { Gestational } \\
\text { age (wks) }\end{array}$ & Mean ${ }^{1}$ & $\begin{array}{l}\text { PI } \\
90 \% \text { interval }\end{array}$ & Mean ${ }^{1}$ & 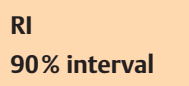 & Mean ${ }^{1}$ & $\begin{array}{l}\text { Vmean } \\
90 \% \text { interval }\end{array}$ \\
\hline 18 & 0.888 & $(0.509-1.407)$ & 0.447 & $(0.222-0.659)$ & 43.458 & $(20.659-71.901)$ \\
\hline 19 & 0.838 & $(0.460-1.356)$ & 0.429 & $(0.204-0.641)$ & 44.025 & $(21.202-72.500)$ \\
\hline 20 & 0.812 & $(0.436-1.328)$ & 0.419 & $(0.194-0.630)$ & 44.831 & $(21.982-73.337)$ \\
\hline 21 & 0.795 & $(0.420-1.309)$ & 0.411 & $(0.186-0.622)$ & 45.704 & $(22.830-74.240)$ \\
\hline 22 & 0.781 & $(0.407-1.293)$ & 0.405 & $(0.180-0.615)$ & 46.545 & $(23.647-75.113)$ \\
\hline 23 & 0.769 & $(0.397-1.280)$ & 0.400 & $(0.175-0.610)$ & 47.301 & $(24.377-75.899)$ \\
\hline 24 & 0.759 & $(0.388-1.268)$ & 0.395 & $(0.171-0.605)$ & 47.945 & $(24.997-76.575)$ \\
\hline 25 & 0.751 & $(0.381-1.258)$ & 0.391 & $(0.167-0.601)$ & 48.473 & $(25.500-77.133)$ \\
\hline 26 & 0.743 & $(0.374-1.248)$ & 0.387 & $(0.163-0.597)$ & 48.889 & $(25.891-77.580)$ \\
\hline 27 & 0.736 & $(0.369-1.239)$ & 0.384 & $(0.160-0.593)$ & 49.206 & $(26.183-77.928)$ \\
\hline 28 & 0.729 & $(0.363-1.230)$ & 0.380 & $(0.157-0.590)$ & 49.439 & $(26.391-78.192)$ \\
\hline 29 & 0.722 & $(0.358-1.222)$ & 0.378 & $(0.154-0.587)$ & 49.604 & $(26.532-78.388)$ \\
\hline 30 & 0.716 & $(0.354-1.214)$ & 0.375 & $(0.152-0.584)$ & 49.716 & $(26.619-78.532)$ \\
\hline 31 & 0.711 & $(0.349-1-207)$ & 0.372 & $(0.150-0.581)$ & 49.790 & $(26.668-78.637)$ \\
\hline 32 & 0.705 & $(0.345-1.199)$ & 0.370 & $(0.147-0.578)$ & 49.836 & $(26.689-78.714)$ \\
\hline 33 & 0.700 & $(0.341-1.192)$ & 0.368 & $(0.145-0.576)$ & 49.863 & $(26.692-78.772)$ \\
\hline 34 & 0.695 & $(0.337-1.185)$ & 0.366 & $(0.144-0.574)$ & 49.878 & $(26.682-78.818)$ \\
\hline 35 & 0.690 & $(0.333-1.178)$ & 0.364 & $(0.142-0.571)$ & 49.886 & $(26.664-78.856)$ \\
\hline 36 & 0.684 & $(0.330-1.171)$ & 0.362 & $(0.140-0.569)$ & 49.889 & $(26.643-78.891)$ \\
\hline 37 & 0.679 & $(0.326-1.164)$ & 0.360 & $(0.139-0.567)$ & 49.891 & $(26.620-78.923)$ \\
\hline 38 & 0.674 & $(0.322-1.157)$ & 0.358 & $(0.137-0.566)$ & 49.891 & $(26.595-78.955)$ \\
\hline 39 & 0.669 & $(0.318-1.150)$ & 0.357 & $(0.136-0.564)$ & 49.891 & $(26.571-78.986)$ \\
\hline 40 & 0.663 & $(0.313-1.143)$ & 0.355 & $(0.135-0.562)$ & 49.891 & $(26.546-79.017)$ \\
\hline 41 & 0.657 & $(0.308-1.134)$ & 0.354 & $(0.134-0.561)$ & 49.891 & $(26.521-79.048)$ \\
\hline 42 & 0.649 & $(0.302-1.125)$ & 0.353 & $(0.133-0.559)$ & 49.891 & $(26.496-79.079)$ \\
\hline
\end{tabular}

1 Smoothed by means of nonlinear regression. 
Tab. 2 Maternal heart rate during pregnancy.

\begin{tabular}{lll} 
Gestational age (wks) & Mean ${ }^{1}$ & $\begin{array}{l}\text { Maternal heart rate } \\
\text { 90\% interval }\end{array}$ \\
\hline 18 & 88.251 & $(63.460-119.174)$ \\
19 & 87.868 & $(63.219-118.612)$ \\
20 & 87.506 & $(63.000-118.072)$ \\
21 & 87.153 & $(62.790-117.541)$ \\
22 & 86.804 & $(62.584-117.014)$ \\
23 & 86.456 & $(62.379-116.488)$ \\
24 & 86.108 & $(62.174-115.961)$ \\
25 & 85.758 & $(61.966-115.433)$ \\
26 & 85.405 & $(61.756-114.902)$ \\
27 & 85.047 & $(61.542-114.366)$ \\
28 & 84.685 & $(61.322-113.825)$ \\
29 & 84.316 & $(61.096-113.278)$ \\
30 & 83.939 & $(60.862-112.723)$ \\
31 & 83.554 & $(60.620-112.160)$ \\
32 & 83.159 & $(60.367-111.586)$ \\
33 & 82.751 & $(60.102-111.000)$ \\
34 & 82.329 & $(59.823-110.400)$ \\
35 & 81.889 & $(59.526-109.782)$ \\
36 & 81.429 & $(59.209-109.143)$ \\
37 & 80.942 & $(58.865-108.478)$ \\
38 & 80.422 & $(58.488-107.780)$ \\
39 & 79.857 & $(58.066-107.037)$ \\
40 & 79.227 & $(57.579-106.229)$ \\
41 & 78.490 & $(56.984-105.313)$ \\
42 & 77.507 & $(56.145-104.153)$ \\
\hline 5 & & \\
\hline
\end{tabular}

1 Smoothed by means of nonlinear regression.

Tab.3 Calculated constants for the individual parameters and growth functions of the uterine artery during pregnancy.

\begin{tabular}{|lllrr|} 
Parameter & a & b & c & \multicolumn{1}{l}{ d } \\
\hline PI & 0.7297 & 0.8718 & -0.2854 & -3.0028 \\
\hline RI & 1.2658 & 5.2466 & -0.1148 & -4.0677 \\
\hline Vean & 1.2062 & 2.9410 & 8.4061 & 5.1368 \\
\hline Maternal heart rate & 0.8978 & 0.6081 & -11.9993 & -7.3735 \\
\hline
\end{tabular}

These alterations are in part the result of the physiological trophoblastic invasion of the spiral arteries and the loss of the musculoelastic coat of the arteries and are in part caused by an increased cardiac output, a decrease of blood viscosity and a gradual reduction of the peripheral vascular resistance in the maternal compartment [23, 24].

The trophoblastic invasion in the first half of gestation proceeds in two phases and causes pronounced hemodynamic changes in the uteroplacental circulation including the reduction of resistance in the uterine vessels. In the second half of gestation, the process of placentation is largely completed which we found to be reflected by only marginal changes in the impedance indices (PI, RI). These observations are consistent with the literature $[1,10,11,25,26]$. Thus, uterine Doppler waveform measurements are similar regardless of the differing Doppler technologies applied.

In order to establish valid reference curves, it is important to provide standardized and reproducible measurements of uterine blood flow velocity combined with an exact definition of the sampling site and assessment of the placenta location [10, 27]. Bewley et al. demonstrated a reduction of impedance indices along the uterine artery with increasing distance from the crossing of the uterine and external iliac arteries [27].

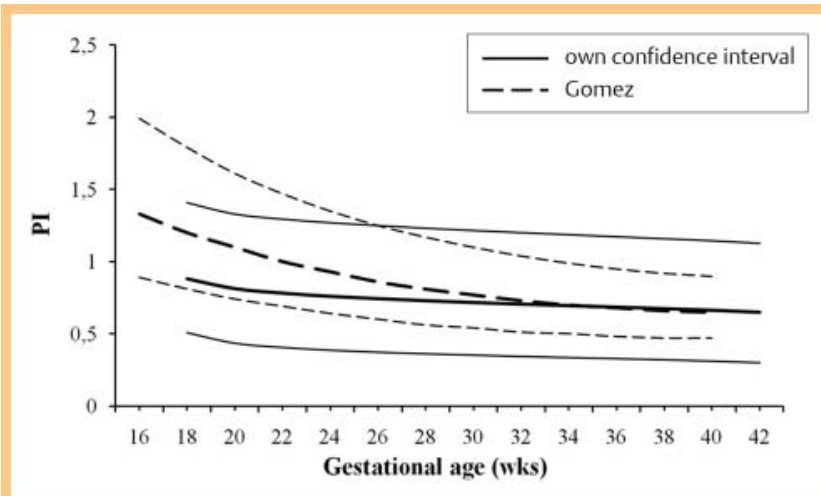

Fig. 7 Comparison of our confidence interval for the pulsatility index (PI) with ranges of Gomez et al. [25].

Abb. 7 Vergleich der eigenen Konfidenzbereiche für den Pulsatilitätsindex (PI) mit den Werten von Gomez et al. [25].

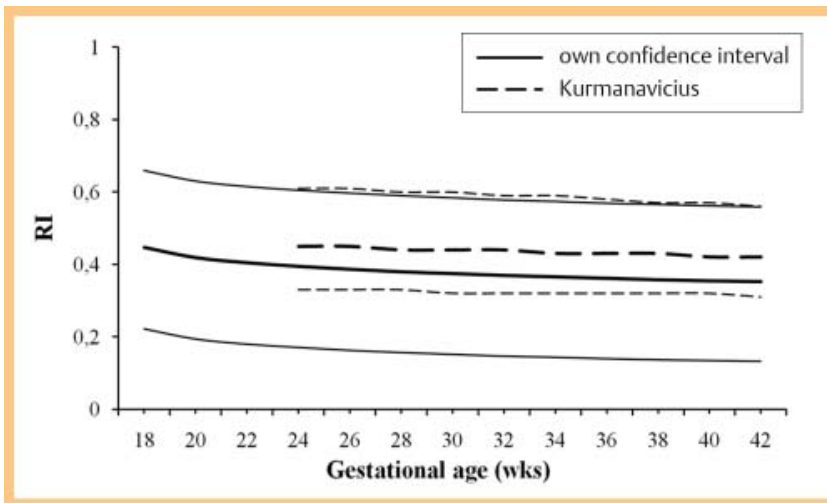

Fig. 8 Comparison of our confidence interval for the resistance index (RI) with ranges of Kurmanavicius et al. [26].

Abb.8 Vergleich der eigenen Konfidenzbereiche für den Resistenzindex (RI) mit den Werten von Kurmanavicius et al. [26].

This may well be explained by the complexity of the uterine collateral vasculature.

In addition, the location of the placenta may have considerable influence on uterine blood flow $[10,27]$. Therefore, we only included measurements in which the placenta location was anterior, posterior or fundal within the uterus. Bower et al. showed significant differences in impedance indices of the uterine artery depending on the site of placentation [10]. Significantly lower PI and RI values were found at the site of placental adherence in comparison to the contralateral side $[10,26,27]$. Although Bewley et al. reported lower resistance indices of the uterine artery when the placenta was located in an anterior position compared to posterior placentation, we were unable to confirm this [27]. A possible explanation could be the use of continuous-wave Doppler in their study, which did not allow standardized reproducible derivation of the uterine blood flow velocity. Even though the uterine blood flow velocity can be measured by continuous-wave Doppler (CW) or pulsed Doppler analysis, only color Doppler ultrasound permits standardized and reproducible derivation of the uterine blood flow velocity. The latter technique has the advantage of allowing accurate localization of the uterine artery with standardized alignment of a low angle 
of insonation and exact positioning of the sample volume [4, 15].

Uterine reference curves with a similar study design and the same examination technique were created by Gomez et al. for the pulsatility index and by Kurmanavicius et al. for the resistance index $[25,26]$. In contrast to these studies, we excluded pregnancies with a unilateral or bilateral post-systolic notch and the placenta in a lateral position within the uterus. Additionally, our data were collected by a single individual while several examiners participated in the collection of data in the other two studies. However, this does not seem to be of great relevance as the interobserver variability is only marginal [27, 28]. Comparison of our reference ranges of the uterine artery to collectives of similar size and homogeneity shows a nearly identical curve progression for the pulsatility index as well as the resistance index $[25,26]$. In comparison to our data, the reference curves published by Kurmanavicius et al. exhibit a marginally narrower confidence interval and slightly increased resistance indices during the entire gestational period, while Gomez et al. feature a wider confidence interval and higher pulsatility indices between the $18^{\text {th }}$ and $24^{\text {th }}$ week of gestation [25, 26]. This could be explained by our exclusion of pregnancies with a unilateral or bilateral post-systolic notch, thus resulting in slightly lower impedance indices. Differing statistical calculation could be a further reason for minor deviations $[16,17,22$, 29].

The evaluation of pathological unilateral or bilateral uterine Doppler waveforms is qualitatively estimated by impedance indices (PI, RI) and demonstration of the post-systolic notch [3, $7,15]$. The latter is viewed as a risk factor for the development of intrauterine growth restriction, pregnancy-induced hypertension and preeclampsia as well as for intrauterine death and a higher placental abruption rate $[2-4,30]$. Although detection of a bilateral notch is associated with a higher complication rate during pregnancy, knowledge of the normal limits of uterine impedance indices is equally important to differentiate normal from pathological pregnancies and for their prognostic assessment. Therefore, accurately constructed reference curves in a well-defined low-risk patient collective are required. A recently conducted bivariable meta-analysis showed that an increased pulsatility index associated with a post-systolic notch in the second trimester of pregnancy has a high predictive value for the development of preeclampsia in a low-risk as well as in a high-risk patient collective [31]. However, the predictive value was lower for intrauterine growth restriction [31]. For the future a combination of biochemical markers with ultrasonographic markers represents a promising approach to improve the prediction of preeclampsia in the first as well as the second trimester of pregnancy [32].

In summary, the present study provides reference curves for the impedance indices (PI, RI), $\mathrm{V}_{\text {mean }}$ and the maternal heart rate in a large well-defined low-risk patient collective and shows similar curve progression compared to the literature. The present reference curves can be applied to the evaluation of uterine blood flow velocity and impedance indices when the placenta is located in a central position.

\section{References}

1 Campbell S, Griffin DR, Pearce JM et al. New Doppler technique for assessing uteroplacental blood flow. Lancet 1983; i: 675-677

2 Chien PFW, Arnott N, Gordon A et al. How useful is uterine artery Doppler flow velocimetry in the prediction of pre-eclampsia, intrauterine growth retardation and perinatal death? An overview. Br J Obstet Gyneacol 2000; 107: 196-208

3 Harrington K, Cooper D, Lees C et al. Doppler ultrasound of the uterine arteries: the importance of bilateral notching in the prediction of preeclampsia, placental abruption or delivery of a small-for-gestationalage baby. Ultrasound Obstet Gynecol 1996; 7: 182-188

4 Kurdi W, Campbell S, Aquilina J et al. The role of color Doppler imaging of the uterine arteries at 20 weeks gestation in stratifying antenatal care. Ultrasound Obstet Gynecol 1998; 12: 339-345

5 Papageorghiou AT, Yu CK, Erasmus IE et al. Assessment of risk for the development of pre-eclampsia by maternal characteristics and uterine artery Doppler. Br J Obstet Gynaecol 2005; 112: 703-709

6 Trudinger BJ, Giles WB, Cook CM. Uteroplacental flow velocity-time waveforms in normal and complicated pregnancy. Br J Obstet Gynaecol 1985; 92: 39-45

7 Zimmermann P, Eiriö V, Koskinen J et al. Doppler assessment of the uterine and uteroplacental circulation in the second trimester in pregnancies at high risk for pre-eclampsia and/or intrauterine growth retardation: comparison and correlation between different Doppler parameters. Ultrasound Obstet Gynecol 1997; 9: 330-338

8 Deutinger J, Rudelstorfer R, Bernaschek G. Transvaginal pulsed Doppler measurement of the blood flow velocity in the pregnant uterus. Ultraschall Klin Prax 1988; 3: 19-24

9 Papageorghiou AT, Yu CK, Bindra R et al. Multicenter screening for preeclampsia and fetal growth restriction by transvaginal uterine artery Doppler at 23 weeks of gestation. Ultrasound Obstet Gynecol 2001; 18: 441-449

10 Bower S, Vyas S, Campbell S et al. Color Doppler imaging of the uterine artery in pregnancy: normal ranges of impedance to blood flow, mean velocity and volume of flow. Ultrasound Obstet Gynecol 1992; 2: 261265

11 Bewley S, Campbell S, Cooper D. Uteroplacental Doppler flow velocity waveforms in the second trimester. A complex circulation. Br J Obstet Gynaecol 1989; 96: 1040-1046

12 Chan FY, Pun TC, Lam C et al. Pregnancy screening by uterine artery Doppler velocimetry - wich criterion performs best? Obstet Gynecol 1995; 85: 596-602

13 Hüneke B, Holst A, Schröder HJ et al. Normal reference values for Doppler flow velocity wave form indices A/B-ratio, Resistance and Pulsatility index obtained from the uterine and umbilical arteries in uncomplicated pregnancies - a longitudinal study. Geburtsh u Frauenheilk 1995; 55: 616-622

14 Gudmundsson S, Marsal K. Umbilical artery and uteroplacental blood flow velocity waveforms in normal pregnancy: a cross sectional study. Acta Obstet Gynecol Scand 1988; 67: 347-354

15 Bower S, Bewley S, Campbell S. Improved prediction of pre-eclampsia by two-stage screening of uterine arteries using the early diastolic notch and color Doppler imaging. Obstet Gynecol 1993; 82: 78-83

16 Altman DG, Chitty LS. Charts of fetal size: 1 . Methodology. Br J Obstet Gynaecol 1994; 101: 29-34

17 Altman DG, Chitty LS. Design and analysis of studies to derive charts of fetal size. Ultrasound Obstet Gynecol 1993; 3: 378-384

18 Bahlmann F, Wellek S, Reinhardt I et al. Reference values of fetal aortic flow velocity waveforms and associated intra-observer reliability in normal pregnancies. Ultrasound Obstet Gynecol 2001; 17: 42-49

19 Bahlmann F, Merz E, Weber G et al. Transvaginal sonographic biometry in early pregnancy - a growth model. Ultraschall in Med 1997; 18: 196-204

20 Merz E, Wellek S. Normal fetal development profiles - a model to obtain standard development graphs for the head and abdominal parameters and the long limb bones. Ultraschall in Med 1996; 17: 153-162

21 Barnett S, Maulik D. International Perinatal Doppler Society. Guidelines and recommendations for safe use of Doppler ultrasound in perinatal applications. J Matern Fetal Med 2001; 10: 75-84

22 Wellek S, Merz E. Age related reference ranges for growth parameters. Meth Inform Med 1995; 4: 523-528

23 Lees MM, Taylor SH, Scott DB et al. A study of cardiac output at rest throughout pregnancy. J Obstet Gynaecol Br Commonw 1967; 74: 319-328

24 Pijnenborg $R$. The placental bed. Hypertens Pregnancy 1996; 15: 7-23

25 Gomez O, Figueras F, Fernandez $S$ et al. Reference ranges for uterine artery mean pulsatility index at $11-41$ weeks of gestation. Ultrasound Obstet Gynecol 2008; 32: 128-132 
26 Kurmanavicius J, Florio I, Wisser J et al. Reference resistance indices of the umbilical, fetal middle cerebral and uterine arteries at 24-42 weeks of gestation. Ultrasound Obstet Gynecol 1997; 10: 112-120

27 Bewley S, Chang TC, Campbell S. Uteroplacental resistance index: analysis of intra- and interobserver variability. Ultrasound Obstet Gynecol 1993; 3: 417-421

28 Pearce JM, Campbell S, Cohen-Overbeek $T$ et al. References ranges and sources of variation for indices of pulsed Doppler flow velocity waveforms from the uteroplacental and fetal circulation. Br J Obstet Gynaecol 1988; 95: 248-256

29 Royston P, Wright EM. How to construct 'normal ranges' for fetal variables. Ultrasound Obstet Gynecol 1998; 11: 30-38
30 Papageorghiou AT, Yu CK, Cicero $S$ et al. Second trimester uterine artery Doppler screening in unselected populations: a review. J Matern Fetal Neonatal Med 2002; 12: 78-88

31 Cnossen JS, Morris RK, terRiet G et al. Use of uterine artery Doppler ultrasonography to predict pre-eclampsia and intrauterine growth restriction: a systematic review and bivariable meta-analysis. CMAJ 2008; 178: 701-711

32 Giguere Y, Charland M, Bujold E et al. Combining biochemical and ultrasonographic markers in predicting preeclampsia: A systematic review. Clin Chem 2010; 56: 361-374 